\title{
VERSÃO BRASILEIRA: A TRADUÇÃO DE ROTEIROS DE AUDIODESCRIÇÃ̃O EM INGLÊS COMO ESTRATÉGIA PARA A PRODUÇÃO DE AUDIODESCRIÇÃO NO BRASIL
}

\section{Brazilian version: the translation of audiodescription rituals in english as a strategy for the audiodescription production in Brazil}

\author{
Versión brasileña: la traducción de roteiros de audiodescripción en inglés como \\ estrategia para la producción de audiodescripción en Brasil
}

Letícia Schwartz ${ }^{*}$

\begin{abstract}
Resumo
A tradução de roteiros de audiodescrição escritos originalmente em idioma estrangeiro pode conferir agilidade ao processo de produção de uma versão brasileira, uma vez que tal estratégia permite dispensar determinadas etapas de trabalho. Este artigo aborda parcialmente os resultados da pesquisa que, sobre este assunto, a autora desenvolveu como trabalho de conclusão da primeira turma do Curso de Especialização em Audiodescrição da Universidade Federal de Juiz de Fora, contando com a orientação da Prof. ${ }^{a}$ Dr. Vera Lúcia Santiago Araújo. Foi proposta, na oportunidade, uma pesquisa prática, comparativa, com o intuito de verificar eventuais benefícios ou desvantagens da tradução de roteiros de audiodescrição com relação à criação de roteiros originais. Para tanto, foram elaborados dois roteiros distintos de uma mesma obra, sendo o primeiro desenvolvido em português e o segundo traduzido a partir da versão americana.
\end{abstract}

PALAVRAS-CHAVE: Acessibilidade. Audiodescrição de Filmes. Tradução de Roteiros de AD

\begin{abstract}
Translating audio description scripts may be a faster way to render a version in the target language, once it can bypass the time constraints observed in certain stages during the creation of a script started from scratch. This paper partially covers the results of the research developed by the author during the first edition of the Curso de Especialização em Audiodescrição at Universidade Federal de Juiz de Fora, under the guidance of Prof. ${ }^{a}$ Dr. Vera Lúcia Santiago Araújo. At the time, the author presented a practical and comparative research, which aimed to verify the benefits and the disadvantages of translating audio description scripts opposed to writing original ones. For this purpose, two different scripts were developed for the same film - one made from scratch, in Portuguese and the other translated from an American version.
\end{abstract}

KEYWORDS: Accessibility. Audio Description of Films. Translating AD Scripts

\section{Resumen}

\footnotetext{
* Especialista em Audiodescrição pela Universidade Federal de Juiz de Fora (UFJF). Mestre em Artes Cênicas da Universidade Federal do Rio Grande do Sul (UFGRS).
} 
La traducción de guiones de audiodescripción escritos originalmente en un idioma extranjero puede tornar más ágil el proceso de producción de una versión brasileña, por tratarse de una estrategia que permite prescindir de ciertas etapas del trabajo. Este artículo expone parcialmente los resultados de la investigación académica que la autora ha desarrollado sobre el tema como trabajo de conclusión del primer grupo del Curso de Especialización en Audiodescripción de la Universidad Federal de Juiz de Fora, contando con la tutoría de la Prof. ${ }^{a}$ Dr. ${ }^{a}$ Vera Lúcia Santiago Araújo. Se propuso, en la oportunidad, una investigación práctica, de naturaleza comparativa, con la intención de verificar eventuales beneficios o desventajas de la traducción de guiones de audiodescripción si comparada a la creación de guiones originales. Para tanto, fueron elaborados dos guiones diferentes para una misma obra: el primero creado directamente en portugués y el segundo construido a partir de la traducción de la versión americana.

PALABRAS ClAVE: Accesibilidad. Audiodescripción de Películas. Traducción de Guiones de Audiodescripción

\section{INTRODUÇÃO}

O desenvolvimento de um roteiro de audiodescrição exige atenção e cuidado. Técnica e arte caminham de mãos dadas ao longo de um processo que conta com diversas etapas de trabalho e a atuação de uma equipe afinada e coesa. A aparente simplicidade do resultado final é diretamente proporcional à dedicação e ao empenho dos profissionais envolvidos. A complexidade da tarefa reflete-se no tempo necessário à sua conclusão e, consequentemente, no custo do serviço.

A busca por alternativas para a dinamização do processo sem prejuízo à qualidade do resultado final possibilita vislumbrar na tradução de roteiros escritos em outros idiomas uma ferramenta para se chegar com maior agilidade a uma versão brasileira. O texto de partida permitiria dispensar algumas das etapas do trabalho, tais como o estudo acerca da obra, a análise detalhada de cada cena e a definição das janelas de inserção. Mesmo a consultoria realizada por pessoa com deficiência visual, determinante para validar a qualidade do roteiro, poderia demandar menos tempo.

O tema tem sido abordado de maneira bastante discreta na literatura disponível sobre a matéria. Foram localizadas contribuições esparsas, quase todas de autoria de pesquisadores estrangeiros. Em Vera (2006), por exemplo, encontra-se um breve relato de experiência com resultados parciais positivos, enquanto Jankowska (2015) apresenta resultados conclusivos, a partir de uma pesquisa avançada com foco na tradução de roteiros de audiodescrição do inglês para o polonês. A autora chega à confirmação da hipótese de que tal procedimento é capaz de preservar a qualidade da audiodescrição, ao mesmo tempo em que reduz o prazo necessário à conclusão do trabalho, assim como os custos do serviço.

Tais discussões não parecem encontrar eco no Brasil. As pesquisas, ou mesmo os registros de experiências realizadas em território nacional, são escassos. Cabe destacar o trabalho de Karine Neumann Gonçalves (2013), no qual a autora relata o processo de tradução de um roteiro de audiodescrição, registrando uma experiência concreta e apontando facilidades e dificuldades desse procedimento a partir da análise de elementos linguísticos e culturais.

A proposta da pesquisa aqui comentada limitou-se a tentar, através de um projeto piloto verificar a viabilidade da tradução de roteiros de audiodescrição para filmes no que se 
refere ao tempo de trabalho e à necessidade de adequação do resultado final aos critérios da produção brasileira.

\section{A tradução de roteiros de audiodescrição}

A fim de melhor compreender o atual panorama da tradução de roteiros de audiodescrição, a pesquisou toma por referência as abordagens de Arma (2011), Bourne e Jiménez Hurtado (2007), Cintas, Orero e Remael (2011), Gonçalves (2013), Jankowska (2015) e Vera (2006). Os textos destes autores apresentam importantes pontos de convergência, dentre os quais destaca-se a formulação - ou mesmo a confirmação - da hipótese de que a tradução de roteiros de audiodescrição do inglês para um idioma diverso é uma estratégia viável para um processo de trabalho mais ágil e econômico. Os autores estão de acordo, ainda, no que se refere às características específicas desse tipo de tradução, que deve contemplar questões técnicas, linguísticas e culturais, e todos apontam a necessidade de promover adequações no texto final, no sentido de obter um resultado coerente para o público-alvo local.

Karine Neumann Gonçalves é responsável pela única referência brasileira no que diz respeito ao assunto em questão. Em seu trabalho de conclusão do curso de Letras-Tradução da UnB (2013), a autora apresenta uma proposta de tradução do roteiro de audiodescrição do longa-metragem Pequena Miss Sunshine, do inglês para o português. Gonçalves coloca em evidência a necessidade de efetuar adequações - tais como a adição, a remoção e a adaptação de informações - para que o roteiro traduzido esteja em consonância com o modelo brasileiro de audiodescrição, favorecendo a leitura da obra por parte do público local. A grande contribuição desse trabalho está na análise dos elementos linguísticos e culturais que fazem com que o roteiro final esteja de acordo com as demandas do público-alvo brasileiro. A autora conclui que a tradução de roteiros de audiodescrição pode ser um recurso viável para tornar o processo de desenvolvimento de um roteiro mais fácil, rápido e econômico, desde que o profissional responsável esteja atento aos diferentes critérios e parâmetros estabelecidos para cada país, a fim de realizar as adequações necessárias.

Anna Jankowska, professora assistente da disciplina de Translation Studies and Intercultural Communication da Universidade Jagiellonian, na Cracóvia, dedicada à pesquisa da viabilidade da tradução de audiodescrição a partir de roteiros originais em língua estrangeira, aponta que algumas das etapas imprescindíveis na elaboração de um roteiro original, como a familiarização com a obra e com o conteúdo em áudio, deixam de ser necessárias quando se trata da tradução de um roteiro já existente em outra língua, possibilitando uma redução significativa do tempo de trabalho.

\section{Características e material da pesquisa}

A pesquisa aqui abordada teve por objetivo validar a tradução de roteiros de audiodescrição para filmes e séries, do inglês para o português, como estratégia de trabalho para a produção de audiodescrição no Brasil. Para tanto, foi proposto o estudo comparativo de 
dois processos distintos: a produção de um roteiro original e a tradução para o português de um roteiro previamente desenvolvido em inglês.

O material escolhido para o experimento proposto foi o primeiro episódio da série de TV Daredevil, personagem conhecido no Brasil como o Demolidor. Dois critérios técnicos foram determinantes nesta escolha: a duração reduzida do episódio (53 minutos), permitindo o desenvolvimento de ambas as versões do roteiro (original e traduzida) em tempo hábil; e a disponibilidade de uma versão dublada, favorecendo a recepção da audiodescrição traduzida e possibilitando uma atuação assertiva por parte dos consultores. Considerou-se, também, a relevância do conteúdo, uma vez que a série retrata um super-herói cego.

O Demolidor é o protagonista de uma série concebida por Drew Goddard a partir dos quadrinhos da Marvel e traz Charlie Cox no papel do herói, Matt Murdock. Um acidente envolvendo uma substância radioativa deixa Matt cego ainda na infância. Como efeito colateral, a exposição a essa substância aguça seus sentidos remanescentes de maneira sobrehumana, além de conferir a Matt uma espécie de radar que lhe permite uma orientação privilegiada, comparável a uma ecolocalização extremamente apurada. Já adulto, Matt atua como advogado durante o dia. À noite, ele é o Demolidor, um herói mascarado que combate o crime nas ruas de Hell's Kitchen, um bairro de Manhattan, na cidade de Nova Iorque. Produzida e veiculada pela Netflix, a série constitui um marco na luta pela acessibilidade: em abril de 2015, a Netflix lançou um comunicado informando que Demolidor seria a primeira produção original da empresa a contar com audiodescrição, atendendo apelos insistentes dos assinantes americanos com deficiência visual, que vinham solicitando a inclusão desse recurso de acessibilidade nos filmes e séries transmitidos por essa provedora de conteúdo audiovisual via internet.

\section{Equipe de trabalho}

A autora do presente artigo, que atua profissionalmente como audiodescritoraroteirista e narradora, assumiu a função de roteirista da versão original em português. Em função do domínio do idioma inglês, foi responsável também pela transcrição e pela tradução do roteiro americano.

O processo de elaboração do roteiro original em português contou com a participação de um consultor técnico, um segundo audiodescritor e um consultor com deficiência visual. $\mathrm{O}$ consultor técnico, um lutador profissional, ofereceu suporte à leitura das cenas de ação. $\mathrm{O}$ segundo audiodescritor colaborou na discussão e nos ajustes do texto. O consultor com deficiência visual foi responsável pela validação do produto final.

Já a tradução teve a colaboração de um consultor com deficiência visual que, neste caso específico, atuou como interlocutor, representando o público-alvo e oferecendo suas impressões enquanto espectador. 


\section{Metodologia da pesquisa}

Inicialmente foram elaboradas duas versões de roteiro de audiodescrição, a primeira consistindo no desenvolvimento de um roteiro original, e a segunda na tradução do roteiro americano para o português. Ambos os processos tiveram como objeto um mesmo episódio "Into the Ring" (No Círculo, na versão em português), o primeiro episódio da série "Daredevil" (Demolidor) -, a fim de conferir coerência à comparação de dados.

O desenvolvimento do roteiro original contou com as seguintes etapas: familiarização com o conteúdo em áudio; familiarização com a obra; pesquisa acerca da série e do personagem; redação do roteiro; consultoria técnica para as cenas de luta; sincronização do roteiro; primeira revisão; segunda revisão (realizada por outro audiodescritor); gravação e edição de rascunho; consultoria por profissional com deficiência visual; ajustes finais e formatação de roteiro para posterior gravação.

A tradução do roteiro contemplou, por sua vez, as seguintes etapas: transcrição da audiodescrição em inglês; tradução; sincronização do roteiro; revisão; finalização e formatação do texto para gravação.

\section{Etapas para o desenvolvimento do roteiro de audiodescrição em português}

\section{$1^{\text {a }}$ etapa: familiarização com o conteúdo em áudio}

Num primeiro momento, foi realizada a audição do filme em versão dublada, sem visualização da imagem. O objetivo era verificar, empiricamente, o grau de compreensão fornecido pelas informações oferecidas por diálogos, trilhas e efeitos sonoros, assim como as sensações e emoções geradas pelo desenho de som.

Foi possível identificar uma série de elementos que precisariam ser esclarecidos pela $\mathrm{AD}$, uma vez que a ausência da imagem poderia ocasionar confusão ou perda de informações.

O desenho de som é extremamente valorizado em Demolidor. Os sons são muito claros, limpos, até mesmo exagerados, como se a intenção fosse propor uma equivalência sonora à estética visual das revistas em quadrinhos.

$2^{\mathrm{a}}$ etapa: familiarização com a obra

É fundamental que o audiodescritor se aproxime da trama e dos personagens na condição de espectador, para poder conduzir os usuários da audiodescrição a uma experiência semelhante. Trata-se de momento destinado a absorver informações e emoções para, posteriormente, identificar os elementos a serem transmitidos na tentativa de levar o espectador com deficiência visual a experimentar as mesmas sensações.

Ao assistir à obra por duas vezes, sempre em versão dublada, tornou-se possível detectar alguns pontos que exigiriam especial atenção do audiodescritor. Matt Murdock, o protagonista, é cego e passa por algumas situações características do cotidiano das pessoas com deficiência visual, circunstâncias que deveriam ser devidamente valorizadas pela $A D$, pois refletem o dia a dia do público-alvo e aproximam o personagem do universo desse grupo específico de espectadores. A complexidade das cenas de luta, que investem em coreografias intensas e precisas, mereceria a consultoria técnica de um profissional da área. 
É recorrente o uso de imagens levemente embaçadas ou o reflexo do interlocutor de Matt nas lentes de seus óculos escuros, caracterizando os momentos em que o personagem consegue identificar se o que estão lhe dizendo é verdadeiro ou falso.

$\underline{3^{a} \text { etapa: estudo sobre a obra }}$

A pesquisa sobre a obra é de suma importância para o desenvolvimento de um roteiro apropriado e a internet facilita em muito essa etapa do trabalho. O apanhado de informações e referências é assimilado pelo audiodescritor, que termina por fazer conexões nem sempre conscientes, mas que oferecem um suporte consistente ao trabalho. A pesquisa, neste caso, também funcionou como ferramenta para definir o vocabulário adequado e o tom do discurso da AD.

$\underline{4^{\mathrm{a}} \text { etapa: redação do roteiro }}$

A redação do roteiro pode ser considerada a etapa mais complexa e delicada do processo. Ela inclui a seleção das informações visuais relevantes e a definição das janelas de inserção, de forma a gerar um texto que se relacione com as informações sonoras do filme segundo critérios de harmonia e coerência.

O documento assim gerado destina-se não apenas ao narrador responsável pela locução do texto, mas também a oferecer suporte ao técnico de áudio que posteriormente fará a edição. A incorporação de uma notação específica, com indicação do tempo preciso de entrada e a deixa sonora, é fundamental na facilitação do trabalho destes profissionais. $\mathrm{O}$ fragmento do roteiro reproduzido a seguir exemplifica essa sistematização:

00:15 [burburinho e buzinas]

Em câmera lenta, um homem caminha entre carros, em um congestionamento. Olha em volta, apreensivo.

Ainda na etapa de redação do roteiro, foi realizado o teste de sincronização, ou seja, uma leitura em voz alta para verificar o ajuste das descrições às janelas de inserção.

$\underline{5^{a} \text { etapa: revisão do roteiro por um segundo audiodescritor }}$

Uma vez finalizada, a primeira versão do roteiro foi encaminhada a um segundo audiodescritor, que contribuiu oferecendo comentários, promovendo discussões e sugerindo ajustes ao texto. A verificação por parte de um segundo audiodescritor é essencial, uma vez que o olhar do profissional responsável pelo projeto pode estar contaminado pelo excesso de informações acumuladas ao longo do processo de trabalho. Um audiodescritor alheio ao percurso traçado até aquele instante terá melhores condições de avaliar o texto desenvolvido. 6 $\sigma^{\text {a }}$ etapa: gravação e edição de rascunho

O texto foi narrado e gravado pela própria roteirista, utilizando um aplicativo convencional para gravação em celular. Em seguida, o material registrado foi editado e ajustado às janelas de inserção disponíveis na versão dublada do filme, utilizando-se para isso o programa Vegas Pro 10.0.

Apesar de não ser o propósito desta etapa, a gravação e a edição funcionaram como um rascunho do resultado sonoro, permitindo identificar problemas como a repetição de termos ou a cacofonia.

$7^{a}$ etapa: consultoria

A consultoria é a etapa em que o roteiro de audiodescrição é avaliado e validado por profissionais com deficiência visual. Esse procedimento é dividido em três momentos. No primeiro, o consultor faz a audição da obra sem audiodescrição, a fim de verificar o grau de compreensão e fruição oferecido pelas informações sonoras do filme. No segundo, o consultor escuta a versão com audiodescrição -por duas vezes, no mínimo- e faz anotações acerca de 
suas observações. No terceiro momento, consultor e roteirista se reúnem para discutir os pontos críticos identificados pelo consultor.

A importância dessa avaliação reside no fato de que o consultor é um representante do público com deficiência visual e não existe expediente algum que possa substituir a vivência cotidiana da deficiência, incluindo noções específicas sobre a leitura de mundo e a configuração de imagens mentais.

$\underline{8^{a} \text { etapa: ajustes finais }}$

$\mathrm{Na}$ última etapa de trabalho, as sugestões apontadas pela consultoria foram incorporadas ao roteiro, que foi formatado e finalizado e em condições de ser encaminhado para uma eventual gravação.

Não foram contabilizadas, em todo este processo, atividades paralelas realizadas com o fim de se chegar a uma imersão no conteúdo e na estética do Demolidor, tais como ler boa parte da série em quadrinhos, conversar com aficionados pelo personagem e assistir a todos os episódios da primeira temporada da série Demolidor. Trata-se de recursos informais que permitem ao audiodescritor deixar-se permear pelo trabalho, ativando uma espécie de antena ou radar que capta qualquer referência ao tema, que invade os sonhos e aparece na sensação difusa do pré-adormecer ou do recém-acordar, em um processo que se assemelha à criação artística.

\section{Etapas para a tradução do roteiro de audiodescrição do inglês para o português}

\section{$\underline{1^{a} \text { etapa: familiarização com a obra }}$}

Apesar desse item não ser mencionado no modelo de Jankowska, julgou-se necessário que o tradutor conhecesse a obra do início ao fim antes de começar ao trabalho. O episódio foi assistido uma única vez, com audiodescrição em inglês.

$2^{\text {a }}$ etapa: transcrição

A audiodescrição da obra foi transcrita, registrando-se os tempos e as deixas de inserção, conforme exemplificado a seguir:

00:15 [distant siren wailing]

A man walks cautiously between cars toward an accident. His face searching. Traffic is stopped. Dozens of pedestrians rush to the scene. His eyes grow alarmed as he shoves his way through the traffic.

A transcrição revelou-se um processo lento, que poderia ser evitado caso fosse possível o contato direto com os produtores da audiodescrição original e o acesso ao roteiro escrito.

$3^{\text {a etapa: tradução }}$

O processo de tradução dividiu-se em três momentos: a tradução interlinguística do roteiro, ajustes de linguagem e tempo, e adequações de conteúdo.

A tradução interlinguística foi o mais simples dos estágios, já que o vocabulário e as estruturas gramaticais utilizados na audiodescrição não apresentam grande complexidade. A dificuldade encontra-se na amplitude do vocabulário da língua inglesa, com termos breves e vívidos que nem sempre têm correspondência exata e concisa em português. 
Os ajustes de linguagem e tempo concentraram-se na busca de estruturas funcionais em português, procurando condições de fluência e harmonia sem alteração de sentido, e na economia de tempo, permitindo que o texto se ajustasse às devidas janelas de inserção.

Também foram alterados trechos que produziam cacofonia ou comprometiam a clareza da locução.

Por fim, foram excluídos termos como "agora", "depois", "então", "enquanto" e "em seguida", visando um texto mais conciso e fluido em português, uma vez que tais advérbios, na maior parte das vezes, estão naturalmente implícitos na sequência natural do discurso.

As alterações efetuadas nesse estágio são exemplificadas abaixo:

Tempo de vídeo: 10:45

$1^{a}$ versão: Matt a surpreende, com seus óculos escuros e sua bengala.

Ajuste: Alteração de verbo para redução do tempo de fala e remoção de pronomes possessivos, visando maior clareza.

Versão final: Matt entra, de óculos escuros e bengala.

Tempo de vídeo: 12:23

$1^{a}$ versão: Uma faca ensanguentada goteja sobre um carpete bege, onde uma mulher está ajoelhada. Ela tem as mãos encharcadas de sangue e está em estado de choque. Visto de cima, um homem de terno está deitado em uma imensa poça de sangue.

Ajuste: Concatenação do texto, visando fluidez. Remoção da posição da câmera por necessidade de redução do tempo de fala. Apesar de relevante para a composição da imagem, a ausência desta informação não interfere na compreensão da cena.

Versão final: Uma faca ensanguentada goteja sobre um carpete bege, onde uma mulher está ajoelhada, com as mãos encharcadas de sangue e em estado de choque. Um homem de terno está deitado em uma imensa poça de sangue.

O último estágio de trabalho, que definiu a necessidade de adequações de conteúdo, foi realizado após análise do material pela audiodescritora-roteirista, com o apoio de um audiodescritor-consultor.

Considerando que a estrutura e o vocabulário da língua inglesa permitem uma maior quantidade de dados em menor tempo, tornou-se necessário selecionar as informações mais relevantes, excluindo-se parte das descrições. Também foram substituídos pronomes pessoais pela denominação do personagem, seja por seu nome ou por uma característica física preestabelecida, em prol de maior clareza do discurso. Outras adequações foram adotadas com relação à terminologia e às estruturas frasais, procurando garantir a fluência e a harmonia do discurso em português.

$\underline{4^{\mathrm{a}} \text { etapa: finalização }}$

Após avaliação dos resultados da tradução, de comum acordo com um consultor com deficiência visual, o roteiro foi formatado e finalizado em condições de ser encaminhado para uma eventual gravação.

Tabela 1: Avaliação Quantitativa do Processo de Tradução do Roteiro de Audiodescrição -

Quadro Comparativo

\begin{tabular}{|l|l|l|}
\hline \multicolumn{1}{|c|}{ ETAPA } & \multicolumn{1}{|c|}{ ROTEIRO ORIGINAL } & \multicolumn{1}{c|}{ ROTEIRO TRADUZIDO } \\
\hline Familiarização com o conteúdo em áudio & 55 minutos & - \\
\hline Familiarizção com a obra & 1 hora e 50 minutos & 55 minutos \\
\hline Estudo sobre a obra & 2 horas e 18 minutos & - \\
\hline Transcrição & - & 7 horas e 38 minutos \\
\hline
\end{tabular}




\begin{tabular}{|l|l|l|}
\hline Redação do roteiro & 14 horas e 14 minutos & - \\
\hline Tradução & - & 11 horas e 03 minutos \\
\hline $\begin{array}{l}\text { Revisão do roteiro por um segundo } \\
\text { audiodescritor }\end{array}$ & 2 horas e 29 minutos & - \\
\hline Gravação e edição de rascunho & 4 horas e 43 minutos & - \\
\hline Consultoria & 3 horas e 42 minutos & - \\
\hline Ajustes finais & 46 minutos & 37 minutos \\
\hline TOTAL & 30 horas e 57 minutos & 20 horas e 13 minutos \\
\hline
\end{tabular}

Fonte: a autora

O tempo despendido para o desenvolvimento do roteiro original em português foi de 30 horas e 57 minutos, enquanto que o processo de tradução do roteiro do inglês para o português totalizou 20 horas e 13 minutos, conforme detalhado na tabela acima. Diversos fatores poderiam reduzir ainda mais o tempo desta segunda opção. Um audiodescritor que já tivesse intimidade com o universo dos quadrinhos ou com o personagem do Demolidor, por exemplo, não necessitaria de uma pesquisa tão demorada quanto a realizada pela audiodescritora desta experiência. A disponibilização do roteiro em inglês em versão escrita, prática que certamente seria adotada no caso de uma iniciativa de exploração comercial do recurso, também diminuiria o tempo e os custos de produção do roteiro traduzido.

\section{Avaliação qualitativa do processo}

O roteiro traduzido foi submetido a uma análise mais profunda, que contou com o apoio de um consultor com deficiência visual. A proposta, neste caso, não se ateve aos parâmetros da consultoria convencional, uma vez que o objetivo era discutir, de maneira colaborativa, o que funcionava ou não na tradução e investigar a natureza das divergências detectadas. As desconformidades assinaladas pela roteirista e pelo consultor foram exaustivamente discutidas e as conclusões foram incorporadas ao roteiro traduzido, definindo, assim, uma versão final.

Foram identificados diversos pontos de incompatibilidade entre as escolhas tradutórias do roteirista responsável pela audiodescrição americana e as orientações básicas para uma audiodescrição de qualidade, como, por exemplo, descrições que não correspondem às imagens, generalizações, informações redundantes, irrelevantes, privilegiadas, imprecisas, insuficientes, etc.

A análise dos principais problemas detectados revela uma maior incidência de ocorrências relativas a informações redundantes e inferências que cabem ao espectador. Em ambos os casos, fica evidente a desconfiança do audiodescritor americano quanto à capacidade de dedução por parte do espectador com deficiência visual.

Para fins dessa pesquisa, os pontos de discordância em relação às escolhas feitas pelo roteirista americano resultaram em alterações no roteiro. No entanto, observamos que essa questão é extremamente delicada e faz refletir sobre os limites éticos dessa estratégia de trabalho. Se a tradução for realizada por um audiodescritor, como defende o presente documento, teremos um profissional apto a identificar falhas do roteiro de partida e a corrigilas. No entanto, isso representa uma interferência, que não pode ser simplesmente ignorada, 
na autoria de um trabalho alheio. Por outro lado, há também um componente ético no fato de difundir uma audiodescrição que esbarra em preceitos fundamentais, em especial no que se refere a subestimar as capacidades de interpretação e inferência da pessoa com deficiência visual. A questão conduz a um novo patamar de discussão, pois a proposta acaba por transcender os limites da tradução ao estabelecer um olhar crítico sobre a autoria.

\section{CONSIDERAÇÕES FINAIS}

A pesquisa comentada neste artigo teve por finalidade verificar a viabilidade da tradução de roteiros de audiodescrição para filmes no que se refere ao tempo de trabalho e à necessidade de adequação do resultado final a critérios técnicos e culturais. A partir do desenvolvimento de um projeto piloto, buscou-se verificar se a tradução de roteiros de audiodescrição para filmes, do inglês para o português, pode tornar-se uma estratégia de trabalho viável e qualificada no processo de implementação da audiodescrição no Brasil.

A tradução de roteiros de audiodescrição envolve dois processos simultâneos: a tradução literária do texto de partida, em inglês, para o texto final, em português; e a tradução visual, ou seja, a tradução da imagem em palavras, uma vez que as escolhas tradutórias dependerão não apenas das opções realizadas pelo roteirista original, mas da fundamentação oferecida pela própria imagem e do conhecimento acerca da relação cultural do público alvo com a obra. A exigência de conhecimentos específicos leva à imposição de que o profissional responsável por tal tradução tenha formação como audiodescritor. Como alternativa, é possível considerar uma parceria entre tradutor e audiodescritor,

Fica clara, nesta análise, a necessidade de uma discussão abrangente e profunda no que se refere à intervenção no texto de partida e aos critérios éticos que relacionados a tal expediente. Sugere-se que futuras reflexões sobre o tema abordem a possibilidade de um roteiro original em português baseado no roteiro em inglês, libertando o profissional responsável dos compromissos inerentes à tradução e evitando configurar qualquer desrespeito à autoria alheia.

Finalmente, vale resgatar um dos tantos pontos de convergência entre os objetivos deste trabalho e daquele desenvolvido por Jankowska, destacando a firme intenção de que a pesquisa possa transcender o âmbito acadêmico e impulsionar o desenvolvimento da $\mathrm{AD}$ em esferas diversas. (Jankowska, p.119). A universalização dessa prática poderia, ainda, promover o intercâmbio entre audiodescritores de diversas nacionalidades que, de uma forma colaborativa, teriam oportunidade de aprimorar-se tecnicamente através do compartilhamento de roteiros. Desta forma, seriam beneficiados o público-alvo, através de maior oferta de produtos acessíveis; os profissionais da área, em função da troca de conhecimentos e experiências; e a própria audiodescrição enquanto ferramenta de acessibilidade, ao adaptar e incorporar diferentes práticas das mais diversas fontes.

\section{REFERÊNCIAS}

ARMA, S. The Language of Filmic Audio Description: a Corpus-Based Analysis of Adjectives. Tese (Doutorado) - Curso de Scienze Psicologiche, Pedagogiche e Linguistiche, 
Dipartimento di Teorie e Metodi Delle Scienze Umane e Sociali, Università Degli Studi di Napoli Federico II, Nápoles, Itália, 2011.

ASOCIACIÓN Española de Normalización y Certificación. UNE 153020:2005 audiodescripción para personas con discapacidad visual requisitos para la audiodescripción y elaboración de audioguías. Madrid, 2005.

BOURNE, J. \& JIMÉNEZ Hurtado, C.. From the visual to the verbal in two languages: a contrastive analysis of the audio description of The Hours in English and Spanish. In: J. D. Cintas, P. Orero, P \& A. Remael (Eds.). Media for All: Subtitling for the Deaf, Audio Description, and Sign Language. Nova Iorque: Rodopi, 2007, p. 175-187.

CHAMBERS, A. C. You're blind, but you see so much: Netflix's Daredevil and blindness. Disponível em: http://thescienceandentertainmentlab.com/daredevil/. Acesso em: $<07 \mathrm{de}$ jun.de 2015>.

DAREDEVIL - Into the Ring. Direção: Phil Abraham. Produção: Kati Johnston Roteiro: Drew Goddard Intérpretes: Charlie Cox; Deborah Ann Woll; Elden Henson; Toby Leonard Moore; Bob Gunton. Música: John Paesano. Netflix, 2015. $1^{\circ}$ episódio da série Daredevil (54 min), son., color. Disponível on demand em: 〈www.netflix.com>.

FRANCO, E. P. C. \& ARAÚJO, V. L. S. Questões terminológico-conceituais no campo da Tradução Audiovisual (TAV). In: Tradução em Revista, 11(02), 2011, p.1-23. Disponível em: http://www.maxwell.vrac.puc-rio.br/trad_em_revista.php?strSecao=input0. Acesso em: $08 \mathrm{de}$ set. 2015.

GONÇALVES, K. N. Traduzindo a tradução: audiodescrição do filme Pequena Miss Sunshine para o público brasileiro com deficiência visual. TCC (Graduação) - Curso de Letras, Departamento de Línguas Estrangeiras e Tradução. Universidade de Brasília: Brasília, Distrito Federal-Brasil, 2013.

JANKOWSKA, A. Translating audio description scripts: Translation as a new strategy of creating audio description. [s.1.]: Peter Lang, 2015.

ORERO, P. Audio Description Behaviour: Universals, Regularities and Guidelines. International Journal of Humanities and Social Science, 2(17), 2012, p.195-202. Disponível em: http://www.ijhssnet.com/journals/Vol_2_No_17_September_2012/19.pdf. Acesso em: $<07$ de jun. de 2015>.

SILVEIRA, D. M. M., FRANCO, E. P. C., CARNEIRO, B. C. S. \& URPIA, A. Audiodescrição para além da visão: um estudo piloto com alunos da APAE. In: V. L. S. Araújo \& M. F. Alderaldo (orgs.). Os Novos Rumos da Pesquisa em Audiodescrição no Brasil. Curitiba: CRV, 2013, p. 201 a 2011.

VERA, J. F. L. Translating Audio description Scripts: The Way Forward? - Tentative First Stage Project Results. Conference proceedings of MUTRA 2006 - Multidimensional Translation: Audiovisual Translation Scenarios. Copenhagen,Denmark, 2006.

Recebido em: 17/10/2019

Aprovado em: 10/12/2019 
